\title{
Condom tamponade in the management of atonic postpartum hemorrhage
}

\section{Ramya Santhanam, Radhamani Mavunkal Viswanathan*, Priya V.}

Department of Obstetrics and Gynecology, Government Medical College, Kottayam, Kerala, India

Received: 20 March 2018

Accepted: 21 April 2018

\section{*Correspondence:}

Dr. Radhamani Mavunkal Viswanathan,

E-mail: drmvradhamani@gmail.com

Copyright: (c) the author(s), publisher and licensee Medip Academy. This is an open-access article distributed under the terms of the Creative Commons Attribution Non-Commercial License, which permits unrestricted non-commercial use, distribution, and reproduction in any medium, provided the original work is properly cited.

\begin{abstract}
Background: Postpartum hemorrhage (PPH) remains a leading direct cause of maternal death in both developed and developing countries. Millennium development goal of reducing maternal mortality rate cannot be achieved unless the prevention and treatment of $\mathrm{PPH}$ is prioritized. Objectives of the study were to study the efficacy of condom tamponade to arrest bleeding in cases of atonic PPH unresponsive to uterotonics.

Methods: Prospective study conducted in the Kottayam Medical College where mothers who develop atonic PPH following childbirth unresponsive to uterotonics (after ruling out traumatic PPH) were included in study. Condom tamponade was applied in them and inflated with normal saline until the bleeding stops. Intrauterine drain was fitted with this to find out ongoing bleeding with tamponade in situ. The Condom tamponade was kept for 12-24 hrs and gradually deflated when bleeding ceased. Outcome measures were (1) Ability of condom catheter to stop bleeding; (2) Cases requiring further intervention; (3) Time required to stop bleeding and (4) Subsequent morbidity in terms of infection.

Results: Of the 487 cases of atonic PPH, 61 required condom tamponade; bleeding controlled in 59 cases $(96.7 \%)$; two patients $(3.3 \%)$ needed further surgical intervention. No cases of maternal mortality due to PPH. No clinical evidence of intrauterine infection.

Conclusions: The hydrostatic condom tamponade controls PPH quickly and effectively. It is simple, inexpensive, easily available, needs less expertise and life saving. Any healthcare provider may use this procedure as a timely measure to save the life of patients especially during referral to decrease ongoing loss.
\end{abstract}

Keywords: Condom tamponade, Management, Atonic PPH

\section{INTRODUCTION}

Postpartum Hemorrhage (PPH) is one of top five causes of maternal death in both developed and developing countries. ${ }^{1}$ The overall prevalence of PPH worldwide is estimated to be 6 to 11 percent. ${ }^{2,3}$ Effective interventions to tackle PPH are actively needed to decrease Maternal Mortality Rate Worldwide. PPH can kill rapidly if not managed in time. Death from postpartum haemorrhage is avoidable by timely detection and management. Uterine balloon tamponade has been included as second line treatment for PPH secondary to uterine atony (especially lower uterine segment), coagulopathy and placenta previa. Millenium developmental goal to reduce maternal mortality can be achieved only if management of PPH is prioritized. ${ }^{4}$

Objectives of present work were to study in a series of patients who had atonic PPH managed by condom tamponade.

- Number of cases where condom catheter stopped bleeding \& time taken to stop bleeding. 
- Number of cases where bleeding continued with condom in situ requiring further intervention.

- Subsequent morbidity in terms of severe infection despite use of prophylactic antibiotics.

\section{METHODS}

This is a prospective descriptive study conducted in the Department of Obstetrics and Gynaecology, Medical College Hospital, Kottayam over a period of 15 months (August 2015-October 2016).

\section{Inclusion criteria}

Women who develop atonic postpartum hemorrhage not responding to uterotonics following normal vaginal delivery/ caesarean section.

\section{Exclusion criteria}

Exclusion criteria were obstetric hemorrhage $<28$ weeks of gestation; traumatic PPH; allergic to latex; acute uterine infection.

\section{Sample size}

Calculated using the formula based on the study conducted by Rathore AM et al as follows ${ }^{5}$ :

$\mathrm{n}=\mathrm{Z}^{2}{ }_{1-\alpha / 2} \mathrm{P}(\mathrm{Q}) / \mathrm{d}^{2}$

$\mathrm{Z} \alpha=1.96$ for $\alpha$ at $5 \%$ level of significance; $\mathrm{P}=$ anticipated population proportion of factor under study; $\mathrm{Q}=1-\mathrm{P} . \mathrm{D}=$ relative precision $(10 \%$ of $\mathrm{P})$

From literature $\mathrm{P}=0.94$ (proportion having Successful management of PPH from study conducted by Rathore AM et al $)^{5}$

$$
\mathrm{n}=3.84 \times .94 \times .06 /(0.94 \times 10 / 100)^{2}=25
$$

\section{Data management and analysis}

The data were entered in Microsoft excel and further statistical analysis was done using the software SPSS.

\section{Study procedure}

Hospital based prospective (descriptive) study conducted in patients who developed intractable atonic PPH not responding to conventional medical management were managed with condom tamponade. Conventional medical management was intravenous oxytocin infusion, $0.2 \mathrm{mg}$ intramuscular ergometrine every 30 minutes for three doses if the uterus remained atonic; $800-1000 \mu \mathrm{g}$ rectal misoprostol and intramuscular prostaglandin F2- $\alpha$ (250 $\mu \mathrm{g}$ every $15-90$ minutes to maximum of $2 \mathrm{mg}$ ) as needed. When these measures failed, balloon tamponade using a condom catheter was applied. Condom tamponade consists of 2 condoms placed over end of Ryle's tube tied with silk to prevent leakage of water. ${ }^{6}$ It also has got one more Ryles tube tied to condom tamponade complex which act as a drain placed in uterine cavity. In patients who had atonic PPH not responding to uterotonics, under aseptic precautions cervix anterior and posterior lips held with valsellum condom catheter is inserted transvaginally high into uterine cavity after ruling out traumatic PPH. Condom is inflated by connecting the other end of Ryle's tube to normal saline $(250-300 \mathrm{ml})$ until the bleeding stops and uterus contracted. Vaginal packing was also inserted to prevent displacement of the condom tamponade. For women who delivered by caesarean, the condom tamponade was inserted either through the uterine incision (pushing the tip to the fundus and the drainage port through the cervix into the vagina) or transvaginally, and the balloon was inflated after the uterine incision was closed. Time taken to control bleeding noted. The uterine fundus was marked as a reference line from which any uterine distention was noted. Drain is placed inside uterine cavity to watch for further bleeding with condom insitu. Bladder continuously drained. Uterine contractility maintained by oxytocin drip for $6 \mathrm{hrs}$. Prophylactic antibiotics were administered intravenously (triple regimen Ampicillin $500 \mathrm{mg}$ every $6 \mathrm{hrs}$, Metronidazole $500 \mathrm{mg}$ every $8 \mathrm{hrs}$, Gentamycin $80 \mathrm{mg}$ every $12 \mathrm{hrs}$ ). Pulse, arterial blood pressure, uterine fundal height, blood in the collection bag of the drainage channel, and the presence of any vaginal bleeding were noted every 30 minutes. Patient temperature was recorded every 4 hours and urinary output. Condom tamponade kept insitu for 12-24 hrs depending on the severity of initial blood loss. After the removal of the vaginal pack, the balloon was deflated slowly over approximately $50 \mathrm{ml} /$ every 30 mins.
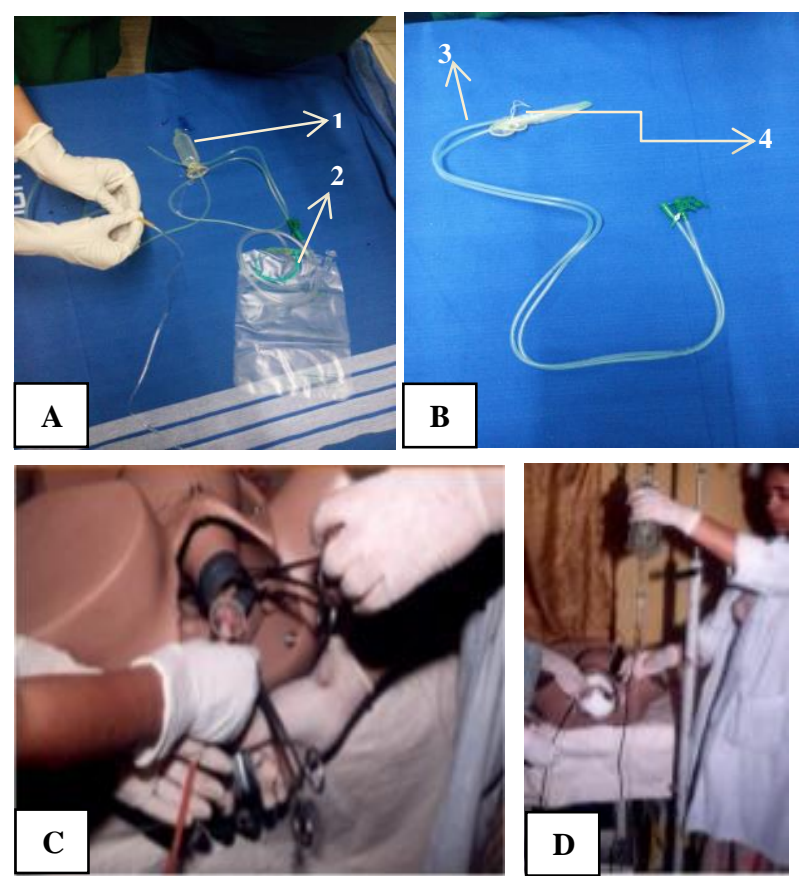

1=Condom tamponade; $2=$ Urobag connected to drain; $3=$ Drain; $4=$ Condom.

Figure 1: (A-D) Condom tamponade. 
If bleeding not controlled within 30 mins of insertion of condom catheter surgical intervention seeked. Failure of the condom tamponade was defined as the persistence of uterine bleeding after the tamponade was properly inflated for 30 minutes with the need for additional procedures to control the bleeding. The procedure was considered to be successful if uterine bleeding stopped or decreased with balloon inflation ${ }^{7}$.

\section{RESULTS}

In this study during the time period of 15 months (August 2015- October 16) there were total 5742 deliveries of which 487 mothers had postpartum haemorrhage $(8.5 \%$ of total deliveries); of which 61 mothers had condom tamponade insertion $(0.1 \%$ of total deliveries and $12.52 \%$ of postpartum haemorrhage). WHO estimates that out of 529,000 maternal deaths every year 136,000 or $25.7 \%$ take place in India where two third occur after delivery, PPH being most leading cause of death $(29.6 \%){ }^{8}$

CRMD (Confidential Review of maternal deaths) in Kerala conducted by Kerala Federation of obstetrics and Gynaecology (KFOG) in the period of 2006-2009 reported that $\mathrm{PPH}$ remains the most common direct cause of death 131 deaths out of 676 were due to obstetric haemorrhage accounting for $19.38 \% .^{9}$

\section{Maternal characteristics}

Age

Most of the patients come under the age group 20-29 years $(67.2 \%)$. Only 1 patient was beyond 40 years (1.6\%); mean age of the patients 27 years.

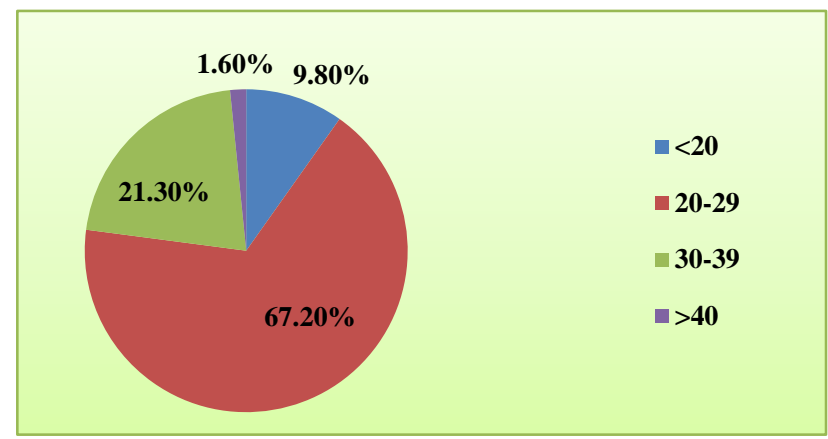

Figure 2: Age distribution of the mothers.

\section{Parity}

Among the 61 patients studied, 31 patients were multipara; accounting for $50.8 \%$ of the total patients. $4.9 \%$ grand multipara patients (who has delivered 5 or more infants). Median parity 2.

In our study among those who had PPH unresponsive to uterotonics $50.8 \%$ were multiparous mothers.

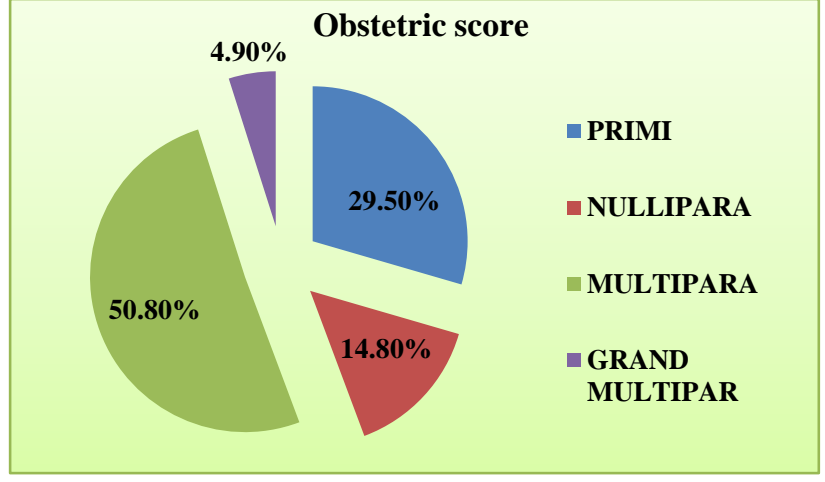

Figure 3: Parity wise distribution of the patient.

\section{Gestational age}

Among the 61 patients, 57 patients were in the gestational age $\geq 37$ completed weeks contributing to $93.44 \%$; only 4 mothers were preterm $<37$ weeks $(6.56 \%)$.

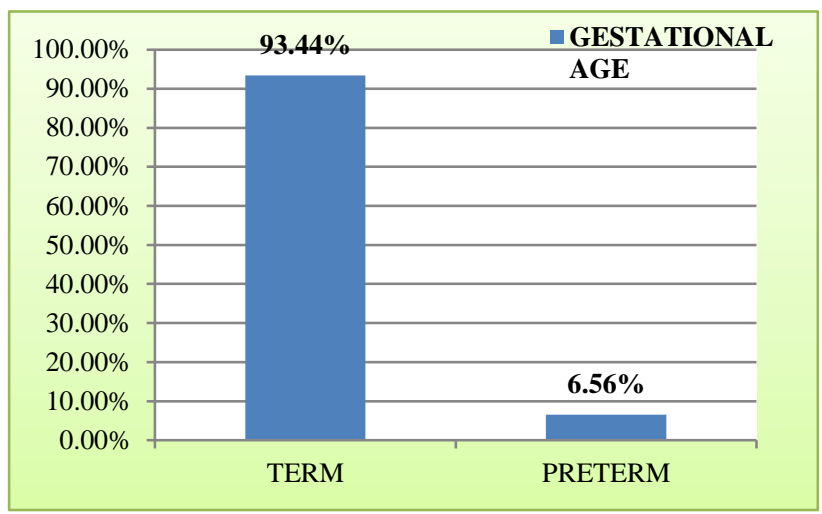

Figure 4: Gestational age of the mothers at the time of parturition.

\section{Induction of labour}

$73.8 \%$ of those who had atonic PPH were induced (45 out of 61 patients). This indicates that PPH is the most common complication of induced labour. Brinsden and colleagues reviewed 3674 normal deliveries and found that the incidence of PPH was increased after induction of labour. ${ }^{10}$ The study of Magann and colleagues suggested an OR of 1.5 (95\% CI 1.2-1.7) for postpartum haemorrhage after induction of labor. ${ }^{11}$

Table 1: Induction of labour.

\begin{tabular}{|lll|}
\hline Induction & Frequency & Percentage (\%) \\
\hline Present & 45 & 73.8 \\
\hline Nil & 16 & 26.2 \\
\hline
\end{tabular}

Mode of delivery

Most patients in whom condom tamponade was applied to control PPH had normal delivery $(50.8 \%)$; 26 patients had instrumental delivery $(42.6 \%) ; 4$ patients had atonic 
PPH unresponsive to uterotonics following LSCS of which one had tamponade insertion abdominally, in whom caesarean was done for failed trial first degree CPD; tamponade successfully controlled bleeding.

Rest three patients had atonic PPH after 4 hrs of LSCS (average); condom tamponade was inserted vaginally and bleeding controlled. Indication for CS being previous CS in 2 out of 3 patients and failed induction in $3^{\text {rd }}$ patient.

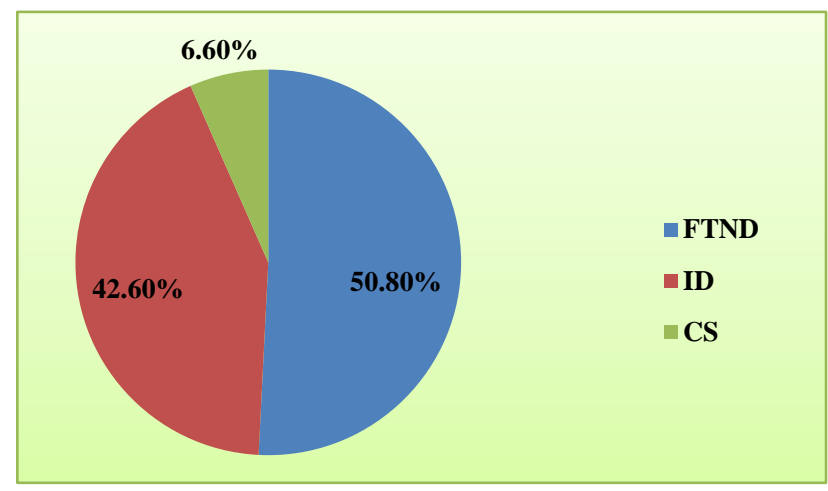

Figure 5: Mode of delivery.

Instrumental deliveries were 26 of which 14 were for failure of secondary powers(vacuum) and 12 prophylactic to cut short second stage ( 8 were vacuum deliveries and 4 forceps deliveries) (in all these cases no traumatic PPH was found). Atonic PPH was controlled successfully with condom tamponade.

\section{Duration of labour}

Atonic PPH more common in patients who had prolonged labour. Cohen analyzed data from 4403 nulliparas and found an increase in PPH rate after prolonged second stage. ${ }^{12} \mathrm{He}$ attributed this to the increased need for midforceps delivery.

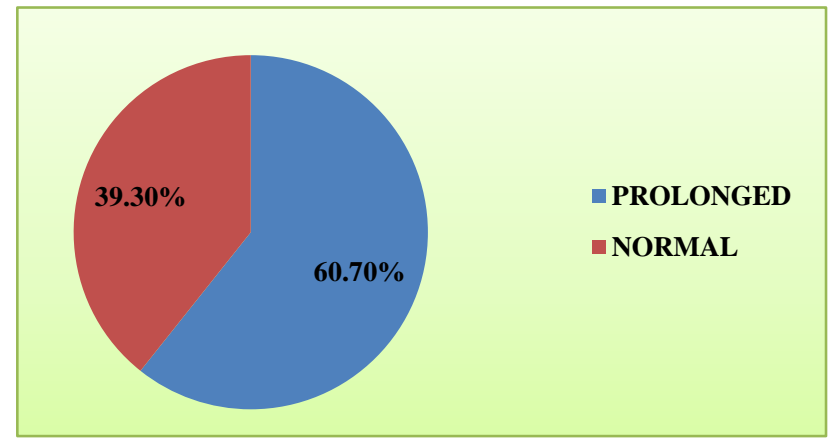

Figure 6: Duration of labour.

In our study duration of second stage of labour is taken into account; prolonged labour if second stage is $>2$ hours in primigravidas and $>1$ hour in multiparas. $\mathrm{PPH}$ was found to be on rising trend in those who had prolonged labour. Probable reason being uterine inertia.

\section{Distribution of baby weight}

PPH was more common in mothers who delivered babies $>3.5 \mathrm{KG}$ accounting for $54.1 \%$ cases.

Table 2: Distribution of baby weight.

\begin{tabular}{|lll|}
\hline Baby Weight & Frequency & Percentage (\%) \\
\hline$<2.5 \mathrm{~kg}$ & 5 & 8.2 \\
\hline $2.5-3.49 \mathrm{~kg}$ & 23 & 37.7 \\
\hline$>3.5 \mathrm{~kg}$ & 33 & 54.1 \\
\hline
\end{tabular}

\section{Severity of PPH}

PPH based on the amount of blood loss (based on gravimetric procedure), were classified into mild, moderate and severe.44.30\% cases mild PPH; 50.80\% were moderate PPH; $4.9 \%$ Severe PPH. Weight of soaked sponges and linen measured and is converted on $\mathrm{ml} / \mathrm{g}$ basis as visual estimation of blood loss is proved to be underestimating the amount of loss. ${ }^{13}$

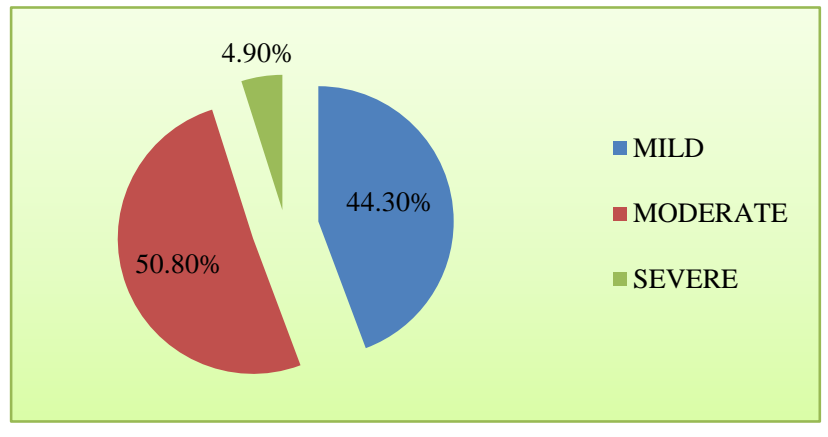

Figure 7: Severity of PPH.

\section{Shock}

Shock index (SI) is used to identify patient in shock. SI HR / SBP. The normal value is $0.5-0.7$. With significant haemorrhage, it increases to 0.9-1.1. The change in SI of an individual patient appears to correlate better in identifying early acute blood loss than the HR, SBP or diastolic blood pressure used in isolation. $54.1 \%$ cases had PPH associated with features of shock with a shock index $>0.7$.

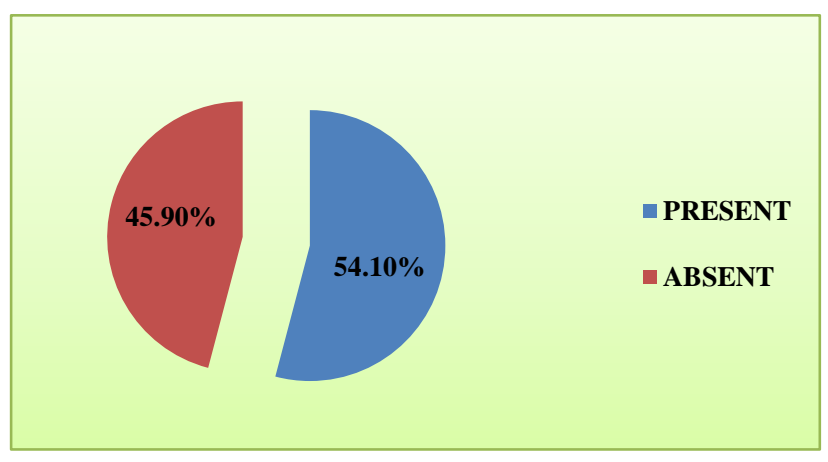

Figure 8: Shock. 


\section{Transfusion}

Blood transfusion given for $55.7 \%$ cases in whom condom tamponade was put to control atonic PPH.

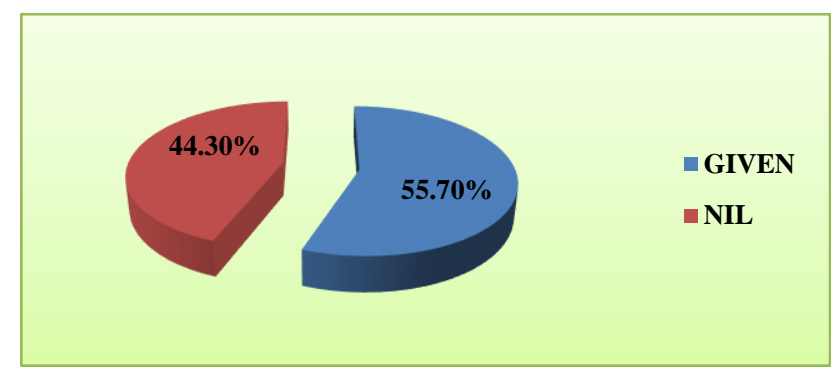

Figure 9: Transfusion.

\section{Time to arrest bleeding}

In $80.3 \%$ cases bleeding got controlled within 15 mins of condom tamponade insertion; in 9 patients bleeding controlled within 15-30 minutes of insertion. In 3 cases bleeding persisted even after 30 minutes and surgical intervention done for 2 of the 3 cases (3.27); in the third patient bleeding was arrested 35 minutes after tamponade application (1.63\%).

Table 3: Time to arrest bleeding.

\begin{tabular}{|lll|}
\hline Time & Number & Percentage \\
\hline$<15$ min & 49 & 80.3 \\
\hline $15-30$ min & 9 & 14.8 \\
\hline$>30$ min & 3 & 4.9 \\
\hline
\end{tabular}

Condom tamponade was retained for a duration of 12-24 hrs in $96.7 \%$.

\section{Bleeding per vaginum with tamponade in situ}

Among the patients who had atonic PPH unresponsive to uterotonics $96.7 \%$ cases bleeding per vaginum was effectively controlled after condom tamponade insertion.

Table 4: BPV with tamponade in-situ.

\begin{tabular}{|lll|}
\hline BPV & Number & Percentage \\
\hline Arrested & 59 & 96.7 \\
\hline Not arrested & 2 & 3.3 \\
\hline
\end{tabular}

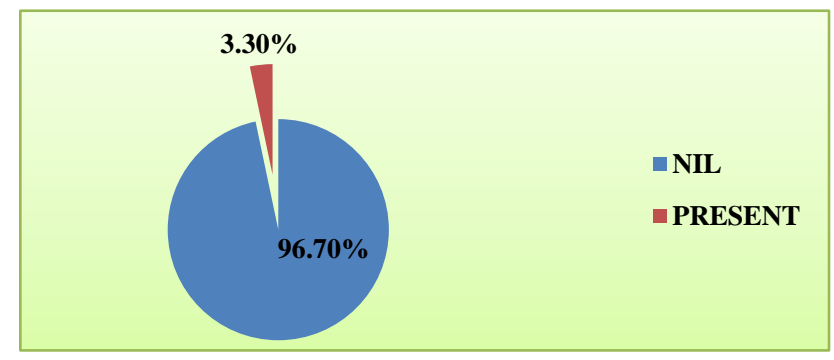

Figure 10: Need for surgical intervention.

\section{Surgical intervention}

2 out of 61 patients were unresponsive for tamponade effect of condom tamponade in whom surgical intervention was done to control bleeding.

\section{DISCUSSION}

In this prospective study (condom tamponade in management of atonic PPH) on mothers who had atonic PPH unresponsive to uterotonics, condom tamponade successfully controlled bleeding in $59(96.7 \%)$ of the 61 women. The condom tamponade was applied in all 61 cases of atonic PPH, including 57 cases after vaginal delivery and 4 after caesarean delivery. It successfully controlled PPH in 59 of 61 cases.

Regarding the secondary outcomes, no cases of maternal fever was found; blood transfusion for 34 cases $(55.7 \%)$ and hysterectomy for $1(1.63 \%)$ women.

The idea of using a condom as a balloon tamponade was first generated and evaluated in Bangladesh in 2001 by Akther ${ }^{14}$ to fill a need and in response to the high cost of commercially available UBT devices.

In present study condom tamponade effectively controlled bleeding (unresponsive to uterotonics) in $96.7 \%$ cases. Only 2 out of 61 cases had continued bleeding despite use of condom tamponade. First case bleeding continued despite condom tamponade administration (even after 30 mins of applying tamponade) and hence laparotomy and surgical intervention was done (Bilateral Uterine Artery ligation and modified B-Lynch suture applied); second case was a referred case after delivery she had atonic PPH managed with uterotonics and was not responding hence was referred to our hospital ; condom tamponade was administered to her and she had shock index of 0.9 and bleeding was persisting despite condom application ; after stabilizing general condition she undergone surgical intervention to stop the ongoing bleeding; subtotal Hysterectomy was performed.

PPH a major composite of obstetric haemorrhage - is ubiquitous as it can kill even a healthy women within 2 $\mathrm{hr}$, if unattended. ${ }^{15}$ Although most can be treated successfully with conservative measures, such as medications, $10 \%$ of the women with $\mathrm{PPH}$ require major surgical interventions and even hysterectomy to save their lives. The recommendation is a step-wise approach to management of post-partum haemorrhage from less invasive therapies like uterine massage and uterotonic drugs to more invasive ones like arterial embolization, uterine compression sutures, uterine artery ligation and ultimately hysterectomy. Condom tamponade is an effective intermediate therapy option that can be implemented by frontline health workers with minimal training. Surgical procedures are invasive, involve laparotomy, requires expertise, associated with 
significant morbidity and compromise future fertility. In contrast condom tamponade is simpler and handy alternative for arresting the bleeding; well recognised therapy in patients of intractable $\mathrm{PPH}$, especially due to atony, coagulopathy and placenta accrete.

In our study it is observed that timely use of condom tamponade can reduce the maternal morbidity (need for laparotomy) and also maternal mortality. The 'golden first hour' is the time at which resuscitation must be commenced to ensure the best chance of survival. The probability of survival decreases sharply if the patient is not effectively resuscitated during the golden first hour of delivery. Condom tamponade is a quick, minimally invasive, easy procedure and life saving if carried out in time ;especially in settings where blood transfusion and surgical facilities may not be readily available. Multiple studies have suggested that many deaths and morbidity (organ failure, transfusion complications, thrombosis, ARDS, sepsis, anaemia, intensive care, and prolonged hospitalization) associated with PPH could be prevented with prompt recognition and more timely and adequate treatment. ${ }^{16-21}$

World Health Organization, the International Federation of Gynecology and Obstetrics, and the Royal College of Obstetricians and Gynaecologists all recommend a uterine balloon tamponade (UBT) if uterotonics and uterine massage fail to control bleeding. . $^{152,23}$ Undoubtedly, UBT is an effective treatment option for control of PPH and it has obtained satisfactory results particularly in the management of uterine atony. ${ }^{24}$

Our study result is comparable to the following studies:

Rathore AM et al a prospective study in a tertiary hospital in India on 18 patients found that condom tamponade was $94 \%$ successful in controlling haemorrhage. ${ }^{5}$

Shaguftha Yasmeen Rather et al evaluated the success of condom tamponade in arresting intractable PPH on 26 cases and concluded that condom tamponade is simple, cheap \& effective (success rate of 96.2\%) alternative to manage a dreaded obstetric complication like PPH encountered frequently and to reduce maternal mortality \&morbidity associated with PPH effectively. ${ }^{25}$

Shivker et al conducted a study at tertiary care facility in India to evaluate the efficacy of condom tamponade on 73 patients with intractable PPH; concluded condom tamponade was successful in controlling PPH in 68/73 patients $(93.2 \%){ }^{26}$

Asmita et al conducted a prospective study in tertiary care hospital in India to study the efficacy and complications of condom tamponade in non traumatic $\mathrm{PPH}$ on18 patients; Concluded that condom catheter is effective in controlling non traumatic PPH in $94 \%$ cases. It is effective, simple to use especially in low resource settings. ${ }^{27}$
Tort et al conducted a randomized controlled trial to test the effectiveness of intrauterine balloon tamponade with condom catheter in severe PPH management. Study included women presenting with PPH refractory to first line management after a vaginal delivery. Outcomes measured were feasibility of recruitment, acceptability of condom catheter by clinicians, its impact on organizing care, its tolerance among women. Concluded that intrauterine condom tamponade is accepted by health staff and the use of this is well tolerated by women in low resource countries. ${ }^{28}$

From this study we can state that condom tamponade saves both time and money with positive results in approximately $96.7 \%$ cases. To conclude condom tamponade is cheap, safe, easily available, needs less expertise, life saving, less time consuming and effective if intervened in time. Especially in low resourse settings can be used to control ongoing bleeding at times of referral.

\section{ACKNOWLEDGMENTS}

Authors express their sincere gratitude to Head of the Department Dr. T.J. Cicily, Dr. Radhamani M.V., Dr. Priya V. for supporting through this study.

Funding: No funding sources

Conflict of interest: None declared

Ethical approval: Not required

\section{REFERENCES}

1. Mousa, Hatem A, Alfirevic Z. Treatment for primary postpartum haemorrhage. Cochrane database syst Rev 1;2003.

2. Carroli G, Cuesta C, Abalos E, Gulmezoglu AM. Epidemiology of postpartum haemorrhage: a systematic review. Best Pract Res Clin Obstet Gynaecol. 2008;22(6):999-1012.

3. Calvert C, Thomas SL, Ronsmans C, Wagner KS, Adler AJ, Filippi V. Identifying regional variation in the prevalence of postpartum haemorrhage: a systematic review and meta-analysis. PLoS One. 2012;7(7):e41114.

4. WHO recommendations for the prevention of postpartum haemorrhage. Geneva, World Health Organization, 2007 http://whqlibdoc.who.int/hq/2007/WHO_MPS_07.06 _eng.pdf. Accessed 4 May 2009.

5. Rathore AM, Gupta S, Manaktala U, Gupta S, Dubey C, Khan M. Uterine tamponade using condom catheter balloon in the management of non-traumatic postpartum hemorrhage. J Obstet Gynaecol Res. 2012;38(9):1162-7.

6. Kandeel M, Sanad Z, Ellakwa H, El Halaby A, Rezk M, Saif I. Management of postpartum hemorrhage with intrauterine balloon tamponade using a condom catheter in an Egyptian setting. Int $\mathbf{J}$ Gynaecol Obstet. 2016;135(3):272-5. 
7. Tsu VD. Postpartum haemorrhage in Zimbabwe: a risk factor analysis. $\mathrm{Br} \mathrm{J}$ Obstet Gynaecol. 1993;100(4):327-33.

8. Malhotra J, Singh S, AICOG Manual on Postpartum Hemorrhage: 59th All India Congress of Obstetrics and Gynaecology; 13-17 January 2016.

9. Paily VP, Ambujam K, Rajasekharan Nair V, Thomas B. Confidential review of maternal deaths in Kerala: a country case study. BJOG. 2014 Sep 1;121(s4):61-6.

10. Brinsden PR, Clark AD. Postpartum haemorrhage after induced and spontaneous labour. Br Med $\mathrm{J}$. 1978;2:855-6.

11. Magann EF, Evans S, Hutchinson M, Collins R, Howard BC, Morrison JC. Postpartum hemorrhage after vaginal birth: an analysis of risk factors. S Med J. 2005;98:419-22.

12. Cohen WR. Influence of the duration of second stage labor on perinatal outcome and puerperal morbidity. Obstet Gynecol. 1977;49:266-9.

13. Prasertcharoensuk W, Swadpanich U, Lumbiganon P. Accuracy of the blood loss estimation in the third stage of labor. Int J Gynaecol Obstet. 2000;71:69-70.

14. Akther S, Begum MR, Kabir Z, Rashid M, Laila TR, Zabeen F. Use of a condom to control massive postpartum hemorrhage. Medscape General Medicine.2003;5(3).

15. World Health Organisation (WHO). The World Health Report 2005:make every mother and child count.Geneva:WHO Press;2005.

16. Berg CJ, Harper MA, Atkinson SM, Bell EA, Brown HL, Hage ML, et al. Preventability of pregnancyrelated deaths: results of a state-wide review. ObstetGynecol. 2005;106(6):1228-34.

17. Kilpatrick SJ, Prentice P, Jones RL, Bell EA, Brown HL, Hage ML, et al. Reducing maternal deaths through state maternal mortality review. J Womens Health (Larchmt). 2012;21(9):905-9.

18. Della Torre M, Kilpatrick SJ, Hibbard JU, Simonson L, Scott S, Koch A, et al. Assessing preventability for obstetric hemorrhage. Am J Perinatol. 2011;28(10):753-60.

19. Mc Lintock C, James AH. Obstetric hemorrhage. J Thromb Haemost. 2011;9(8):1441-51.
20. ACOG Practice Bulletin: Clinical Management Guidelines for Obstetrician-Gynecologists Number 76, October 2006: postpartum hemorrhage. Obstet Gynecol 2006 Oct;108(4):1039-47.

21. Zelop CM. Postpartum hemorrhage: becoming more evidence-based. Obstet Gynecol. 2011;117(1):3-5.

22. FIGO Safe Motherhood and Newborn Health Committee, FIGO guidelines: prevention and treatment of postpartum hemorrhage in low-resource settings. Int J Gynecol Obstet. 2012;117:108-18.

23. The Royal College of Obstetricians and Gynaecologists. Prevention and management of postpartum haemorrhage. RCOGGreen-Top Guideline 52, The Royal College of Obstetricians and Gynecologists, 2009.

24. Dabelea V, Schultze PM, McDuie Jr. RS. Intrauterine balloontamponade in the management of postpartum hemorrhage. Am Journal of Perinatology. 2007;24(6):359-64.

25. Rather SY, Qadir A, Parveen S, Jabeen F. Use of Condom to Control Intractable PPH. Practical Man Exp Clin Pharmacol. 2010;12(3):127-9.

26. Shivkar KS, Khadilkar SS, Gandhewar M. Pressure balloon therapy in uncontrolled obstetrical haemorrhage. J Obstet Gynecol India. 2003;53:33841.

27. Rathore AM, Gupta S, Manaktala U, Gupta S, Dubey C, Khan M. uterine tamponade using condom catheter balloon in the management of non.traumatic postpartum hemorrhage. J Obstet Gynaecol Res. 2012;38:1162-7.

28. Tort J, Hounkpatin B, Popowski T, Traore M, Bodin C, Perrin R, et al. A Randomized Controlled Trial to Test the Effectiveness of Intrautetine Balloon Tamponade with Condom Catheter in Severe Postpartum Hemorrhage Management: A Feasibility Study in Benin. J Women's Health Care. 2013;2:135.

Cite this article as: Santhanam R, Viswanathan RM, Priya V. Condom tamponade in the management of atonic postpartum hemorrhage. Int J Reprod Contracept Obstet Gynecol 2018;7:2276-82. 